\title{
Selective solid electrolyte sensors for trace gas concentrations
}

\author{
J. Zosel ${ }^{1}$, M. Schelter ${ }^{1}$, C. Vonau ${ }^{1}$, U. Guth ${ }^{1}$, M. Mertigi,2 \\ ${ }^{1}$ Kurt-Schwabe-Institut für Mess- und Sensortechnik e.V. Meinsberg, Kurt-Schwabe-Straße 4, \\ 04736 Waldheim, Germany, \\ 2 Technische Universität Dresden, Professur für Physikalische Chemie, Mess- und Sensortechnik, \\ 01062 Dresden, Germany \\ zosel@ksi-meinsberg.de
}

\begin{abstract}
:
The measurement of a variety of combustibles such as hydrocarbons (HC), carbon monoxide and hydrogen is an important task for the evaluation of combustion and industrial processes. Solid electrolyte gas sensors based on yttria-stabilized zirconia (YSZ) are suited for many of these applications due to their broad measuring range, short response time and outstanding long-term stability. Their selectivity for single analytes in complex matrices however often needs significant improvement. In this contribution, different approaches for that task are described, which are directed on the electrode material, the electrochemical method of signal generation and the chromatographic pre-selection of analytes. It is shown, that every approach enables significant increase of selectivity without disturbing the other sensor parameters.
\end{abstract}

Key words: YSZ, hydrogen, sensor, coulometry, dynamic methods

\section{Introduction}

The measurement of a variety of combustibles such as hydrocarbons ( $\mathrm{HC})$, carbon monoxide or hydrogen is an important task for the evaluation of combustion processes and industrial high temperature methods [1, 2]. Especially, the reliable measurement of small hydrogen concentrations in air or other mixtures is an important issue for safety and quality monitoring in a developing hydrogen economy as well as for health care applications. Till now, only few sensors are commercially available which can be utilized for the long-term stable and selective online measurement of hydrogen traces in air or other mixtures [3]. As described in [4, 5], none of these sensors fulfill each requirement of applications coming with modern hydrogen related energy conversions.

Generally, solid electrolyte gas sensors can be operated by measuring a voltage (potentiometrically), a diffusion limited current (amperometrically) or a volume- or flow-limited current (coulometrically) [6]. These basic types of solid electrolyte gas sensors exhibit a poor selectivity for single gaseous components when operated in complex mixtures. An enormous amount of research and development activities has been invested till now to improve the selectivity of solid electrolyte gas sensors [7-9].
The motivation for that goal was the combination of the outstanding sensor parameters such as long-term stability, very short response times [10] and a comparably broad measuring range with improved selectivity.

The approaches developed for selectivity improvement for this kind of gas sensors can be classified by the following categories:

- introduction of tailored materials for sensor electrodes and electrolytes [11, 12],

- usage of different materials in multielectrode-sensors [13],

- pre-separation of analytes [14], for example by a chromatographic column (Here the solid electrolyte sensor is the detector, like a flame ionization detector),

- combination of different operating principles [15],

- variation of sensor temperature and volume flow around the sensor [16] and

- temporal variation of polarization voltages, sensor currents and measurement regimes $[17,18]$.

The last two categories are denominated as dynamic methods and are also used successfully for metal oxide sensors [19]. 
In this contribution, three of the above mentioned approaches for the selectivity improvement of sensors based on yttria-stabilized zirconia (YSZ) as solid oxygen ion conductor are described and ways for further improvements with respect to hydrogen trace measurements are discussed.

\section{Experimental}

The schemes of the newly developed sensors and operation methods are presented in Fig. 1. All investigated sensors are based on 8 molepercent YSZ as the solid electrolyte.

The sensor given in Fig. 1A generates its voltage signal by the establishment of a mixed potential at a catalytically less active measuring electrode in comparison to the potential of an equilibrium electrode. Both electrodes are situated in the same measuring gas atmosphere. These sensors were equipped with a broad variety of measuring electrodes made from different materials like noble metals and alloys of them, composites of noble metals and metal oxides as well as mixed oxides like perovskites, while the reference electrode was made of platinum. The sensors were manufactured by screen printing and firing the electrodes, the YSZ electrolyte and the contact pads as described elsewhere [20]. They were tested in different gas mixtures at optimized temperatures, adjusted by the controlled backside heater. It should be mentioned, that sensors according to Fig. $1 \mathrm{~A}$ with both electrodes in the same gas atmosphere require a certain amount of oxygen in the measuring gas. This is not the case for all other solid electrolyte sensors.

The tubular design of the commercially available solid electrolyte cell given in Fig. 1B is different. This cell is equipped with two $\mathrm{Pt}$ mesh electrodes, one placed in the inside measuring gas flow and the other one in the surrounding reference gas air. The investigations with this sensor were directed on dynamic variations of the electrode polarization and the possibility to separate signals for $\mathrm{H}_{2}$ or $\mathrm{CO}$ applied together with $\mathrm{O}_{2}$ in non-equilibrated $\mathrm{N}_{2}$ diluted gas mixtures [21].

The third approach to measure $\mathrm{H}_{2}$ traces with high selectivity in oxygen containing mixtures like air with solid electrolyte sensors is illustrated in Fig. 1C. It utilizes the chromatographic pre-separation of $\mathrm{H}_{2}$ by combined silica/molecular sieve columns and its subsequent detection with a fast responding coulometric solid electrolyte cell (No. 14 in Fig. 1C) of the design given in Fig. 1B [22]. This setup was investigated and optimized for a low limit of detection requiring the precise quantification of all non-Faradaic currents in the cell.

\section{Results}

A) Mixed potential sensors

Mixed potential sensors with different electrode materials can be used to measure $\mathrm{H}_{2}-$ concentrations in the lower ppm range. An example of the response of one of the various investigated electrode materials is illustrated in Fig. 2. Here, for the measuring electrode a composite material was used, made of the conductive polymer polyaniline (PANI) and oxides of $\mathrm{Fe}$ and $\mathrm{Co}$ by adding $0.075 \mathrm{~mol} \mathrm{FeCl}_{3}$ and $0.025 \mathrm{~mol} \mathrm{Co}\left(\mathrm{NO}_{3}\right)_{2}$ to the polymerization solution as described in [20]. The sensitivity to $\mathrm{H}_{2}$ is lower than for hydrocarbons like propene and depends strongly on temperature. By applying other composite materials made of, e.g., Au and $\mathrm{Ta}_{2} \mathrm{O}_{5}$ to prepare the mixed potential measuring electrode, the selectivity for hydrogen can be significantly increased as the comparison between the curves depicted in Fig. 3 reveals. Details of the preparation of such electrodes are published elsewhere [23].
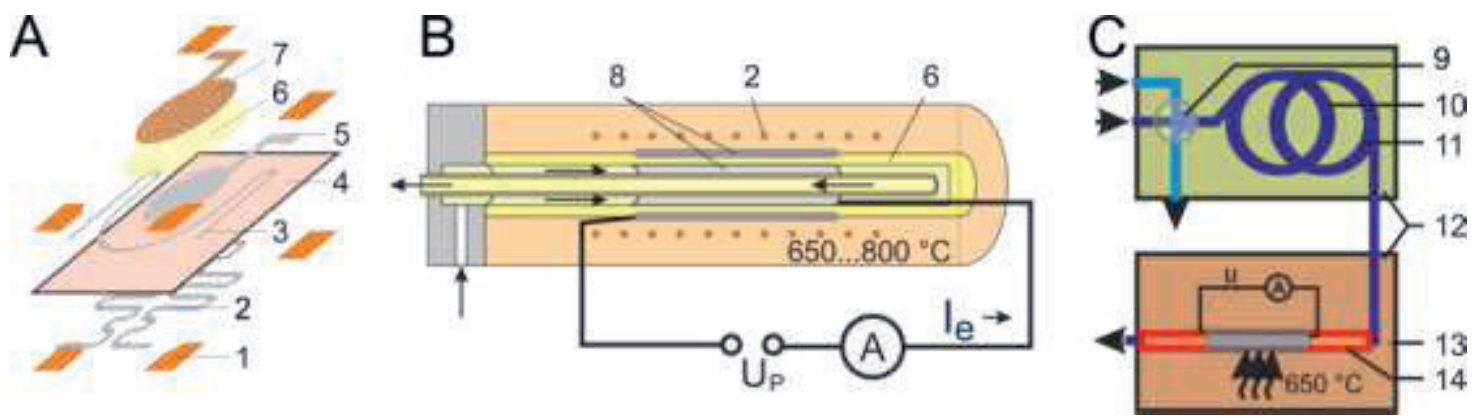

Fig.1. Schemes of the different approaches for selectivity improvement:

A: Mixed potential sensor with tailored electrode material (1 contact pad, 2 heater, 3 temperature resistor, 4 alumina substrate, 5 reference electrode, 6 solid electrolyte, 7 measuring electrode).

B: Tube-type solid electrolyte sensor (8 Pt electrodes).

C: Chromatographic setup (9 sample loop, 10 silica column, 11 mol sieve column, 12 chromatographic unit, 13 coulometric detector, 14 solid electrolyte cell). 


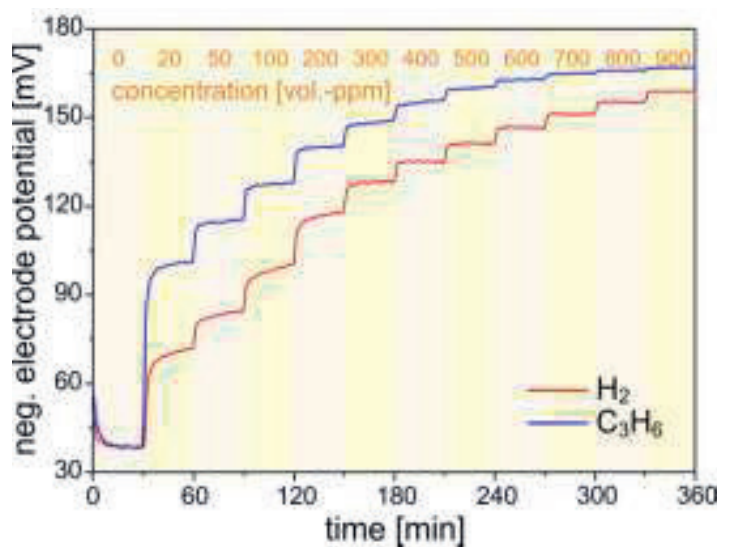

Fig.2. Response behavior of a mixed potential solid electrolyte sensor with a measuring electrode made of polymer/metal oxide composite, $\varphi\left(\mathrm{O}_{2}\right)=1.5 \mathrm{vol} . \mathrm{-} \%, \vartheta=450^{\circ} \mathrm{C}$.

Concluding the efforts invested in material optimization of mixed potential sensors, it can be stated that it is possible to elevate the selectivity of those sensors for hydrogen to values near to 1 , but long-term stability as well as a limit of detection below 1 vol.-ppm are still issues to be addressed by further developments.

\section{B) Dynamic polarization}

Since electrochemical reactions of gaseous analytes at electrodes on solid electrolytes occur at different potentials, they also should result in peak-shaped currents in voltammograms as it is known from liquid analytes. This phenomenon was investigated by applying voltammetric polarization regimes to a tube-shaped solid electrolyte cell, which was purged with gaseous mixtures of hydrogen or carbon monoxide together with oxygen, diluted in nitrogen [21]. Varying temperature, electrode area, volume flow and temporal gradient of electrode potential it was possible to optimize the conditions to measure the different concentrations in the non-equilibrated gases separately.

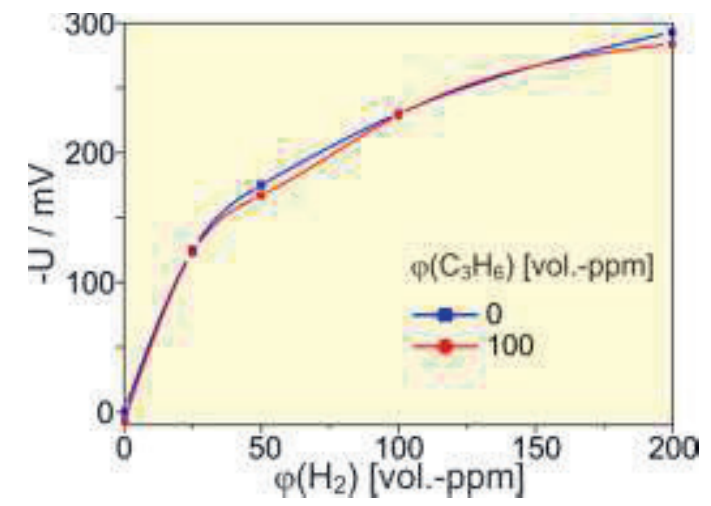

Fig.3. Cross sensitivity to $\mathrm{C}_{3} \mathrm{H}_{6}$ of a mixed potential solid electrolyte sensor with a measuring electrode made of $\mathrm{Au} / \mathrm{Ta}_{2} \mathrm{O}_{5}$-composite in $\mathrm{H}_{2}$-containing mixtures with $\varphi\left(\mathrm{O}_{2}\right)=21 \mathrm{vol} .-\%, \vartheta=550{ }^{\circ} \mathrm{C}$.
As shown in Fig. 4, hydrogen related peaks develop at potentials between -400 and $-200 \mathrm{mV}$ versus air reference electrode. The expected increases of peak height and area were found in the $\mathrm{H}_{2}$ concentration range between 0 and 100 vol.-ppm. They are not linear as it is usually the case for voltammetric peaks but follow a logarithmic curve with a similar shape like the curves in Fig. 3.

It could be demonstrated that the height of the hydrogen related peak at around 70 vol.-ppm $\mathrm{H}_{2}$ obeys the Randles-Sevčik equation (RSE), if the temporal gradient of the electrode potential does not exceed $50 \mathrm{mV} / \mathrm{s}$.

The $\mathrm{CO}$ related peaks were found to arise in the same potential region and at the same potential gradient like the $\mathrm{H}_{2}$-related peaks as it is shown in Fig. 5. Here the peak height and area increase linearly up to $\mathrm{CO}$ concentrations of 500 vol.-ppm. At lower $\mathrm{CO}$ concentrations the peak is relatively broad and develops sometimes two maxima, depending on the scan rate. This leads to the assumption that the CO oxidation can be kinetically distinguished in different steps. This characteristic peak form can be seen clearly in Fig. 6 showing the dependency on the scan rate at $\varphi(C O)=200$ vol.-ppm. The peak height increases linearly with the square root of the scan rate (RSE) up to scan rates of $20 \mathrm{mV} \cdot \mathrm{s}^{-1}$

Oxygen results also in voltammetric peaks in these non-equilibrated diluted mixtures, which develop at significantly higher scan rates than the peaks of $\mathrm{H}_{2}$ and $\mathrm{CO}$. These oxygen related peaks occur at cathodic scan gradients between potentials of -100 and $-300 \mathrm{mV}$, as it is illustrated in Fig. 7. Here a linear increase of peak height was found in the complete investigated concentration range till 500 vol.-ppm.

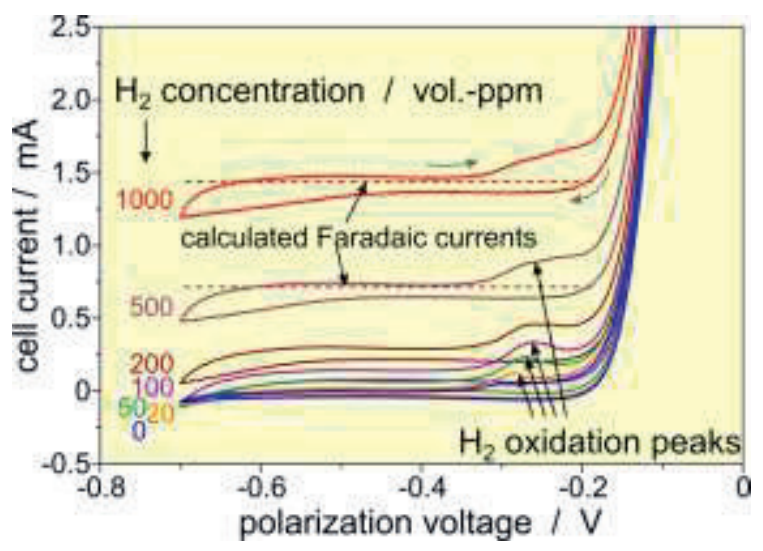

Fig. 4. Voltammograms at a solid electrolyte cell acc. to Fig. $1 B$ in gases with different hydrogen concentrations, cell temperature: $750{ }^{\circ} \mathrm{C}$, flow rate: $10 \mathrm{sccm}$, electrode area: $7.5 \mathrm{~cm}^{2}$, scan rate: $10 \mathrm{mV} \cdot \mathrm{s}^{-1}$. 


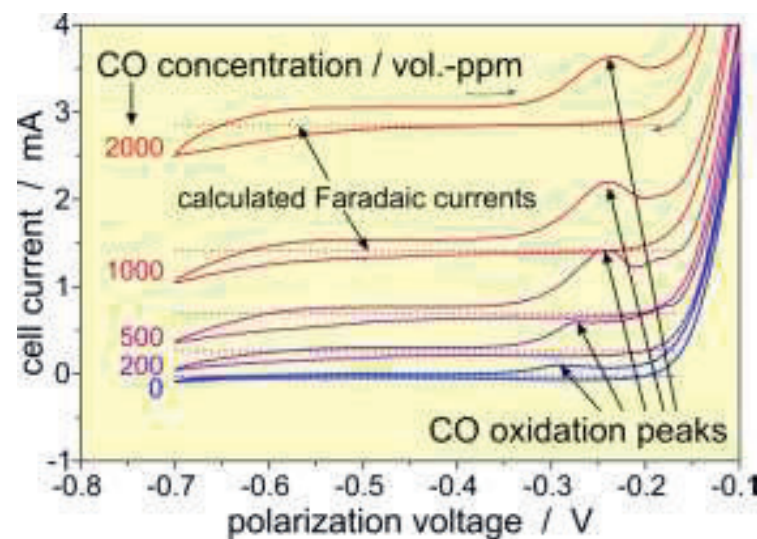

Fig. 5. Voltammograms at a solid electrolyte cell acc. to Fig. $1 B$ in gases with different carbon monoxide concentrations, cell temperature: $750^{\circ} \mathrm{C}$,

flow rate: $10 \mathrm{sccm}$, electrode area: $7.5 \mathrm{~cm}^{2}$, scan rate: $10 \mathrm{mV} \cdot \mathrm{s}^{-1}$.

Varying the scan rate of voltammetric measurements enables, therefore, an efficient separation between combustible and oxygen related peaks. The peak properties found for the three investigated gases are summarized in Table 1.

C) Chromatographic pre-separation

The most complex requirements to selectivity are caused by applications with more than three components to be measured with one solid electrolyte sensor. These can benefit often from a pre-separation of the analytes in an adapted chromatographic column. Solid electrolyte coulometric sensors are basically well suited to serve as detectors for gas chromatographic systems, since they have a broad measuring range of more than 7 orders of magnitude and short response times in the millisecond range [24]. Nevertheless, they are commonly not introduced in this field of analytics like thermal conductivity detectors or flame ionization detectors. One reason consists in their limit of detection (LOD) that was too high for most applications.

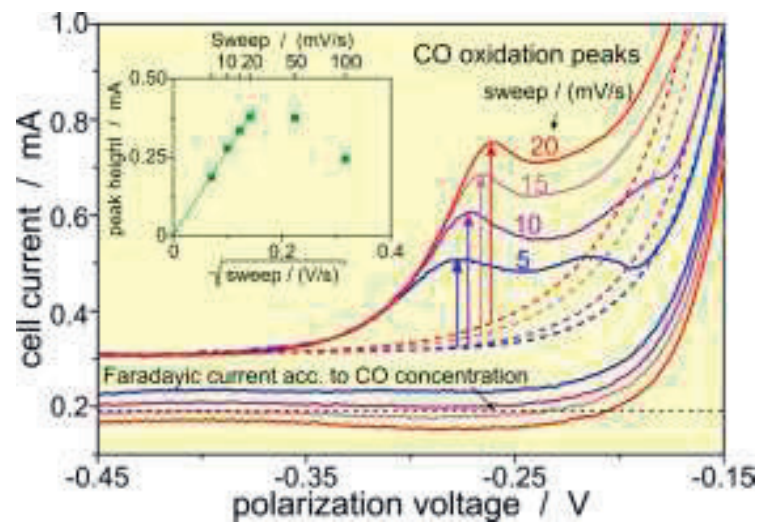

Fig. 6. Voltammograms at a solid electrolyte cell acc. to Fig. $1 B$ in a gas mixture with $\varphi(C O)=200$ vol. ppm at different scan rates, cell temperature: $750{ }^{\circ} \mathrm{C}$,

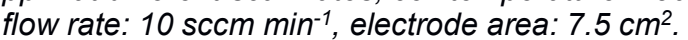

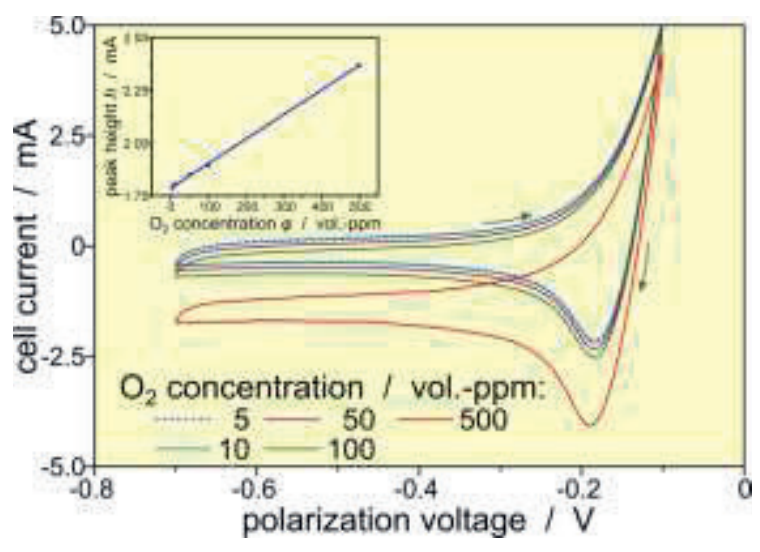

Fig. 7. Voltammograms at a solid electrolyte cell acc. to Fig. $1 B$ at different oxygen concentrations, cell temperature: $750{ }^{\circ} \mathrm{C}$, flow rate: $10 \mathrm{sccm}$, electrode area: $7.5 \mathrm{~cm}^{2}$, scan rate: $200 \mathrm{mV} \cdot \mathrm{s}^{-1}$.

Tab. 1: Peak parameters of voltammetrically determined combustibles and oxygen

\begin{tabular}{|l|l|l|l|l|}
\hline gas & $\begin{array}{l}\text { peak } \\
\text { potential } \\
\text { range } \\
{[\mathrm{mV}]}\end{array}$ & $\begin{array}{l}\text { scan } \\
\text { direct./ } \\
\text { rate } \\
{[\mathrm{mV} / \mathrm{s}]}\end{array}$ & $\begin{array}{l}\text { RSE } \\
\text { validity } \\
{[\mathrm{mV} / \mathrm{s}]}\end{array}$ & $\begin{array}{l}\text { max. peak } \\
\text { height } \\
\text { increase } \\
\text { [vol.-ppm] }\end{array}$ \\
\hline $\mathrm{H}_{2}$ & $\begin{array}{l}-400 / \\
-200\end{array}$ & $\begin{array}{l}\text { anod./ } \\
10\end{array}$ & 50 & $\begin{array}{l}100 \\
\text { (non-lin.) }\end{array}$ \\
\hline $\mathrm{CO}$ & $\begin{array}{l}-400 / \\
-200\end{array}$ & $\begin{array}{l}\text { anod./ } \\
10\end{array}$ & 20 & $\begin{array}{l}500 \\
\text { (linear) }\end{array}$ \\
\hline $\mathrm{O}_{2}$ & $\begin{array}{l}-100 / \\
-300\end{array}$ & $\begin{array}{l}\text { cathod./ } \\
200\end{array}$ & $\begin{array}{l}\text { no } \\
\text { RSE }\end{array}$ & $>500$ \\
\hline
\end{tabular}

Therefore, it was obvious to investigate the reasons for the elevated limit of detection and to find approaches for repressing their influence. The results of these investigations reveal that the most important sources for that phenomenon are non-Faradaic currents caused by electronic conductivity of the solid electrolyte as well as electrochemical and physical noise. Reducing these non-Faradaic currents consequently as it is described in [25], chromatographic systems were developed for monitoring gaseous extracts from biogas processes [26]. The calibration of these systems proves that the peak areas, measured with the chromatographic solid electrolyte detector, follow the Faraday law as the curves in Fig. 8 indicate. Therefore, the detector could be proved to be calibrationfree over more than one year. The measures taken to diminish the non-Faradaic currents enable a lowering of the LOD over more than two orders of magnitude. Now the chromatographic measurement of hydrogen peaks can be performed down to concentrations below 100 vol.-ppb as it is shown in Fig. 9. This very low limit of detection enables the application of those systems for medical breath gas measurement. 


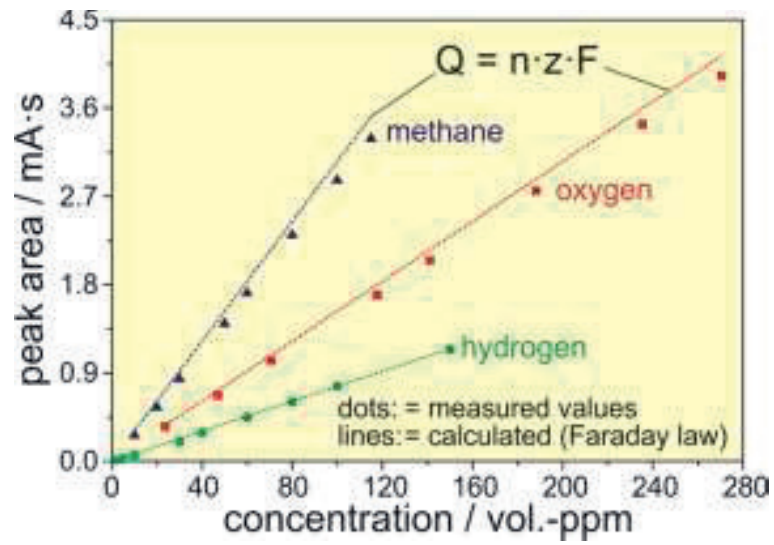

Fig. 8. Calibration results of chromatographic separation of a 3-component mixture diluted in $\mathrm{N}_{2}$ with the setup in Fig. $1 \mathrm{C}$, detector temperature: $750{ }^{\circ} \mathrm{C}$, injected gas volume $1 \mathrm{~mL}$

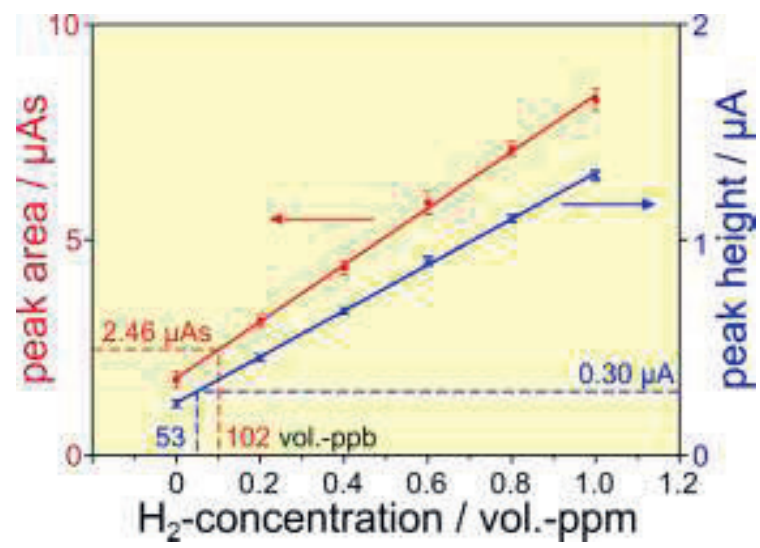

Fig. 9. Limit of detection for $\mathrm{H}_{2}$ of the setup in Fig. $1 \mathrm{C}$, determined with a standard mixture of $\mathrm{H}_{2}$ in $\mathrm{N}_{2}$, detector temperature: $750{ }^{\circ} \mathrm{C}$, injected volume: $1 \mathrm{~mL}$

An example of this application is shown in Fig. 10 with hydrogen related peaks measured in the breath gas of different persons and in laboratory air. This example reveals that chromatographic pre-selection enables the selective detection hydrogen traces in air with a non selective solid electrolyte sensor.

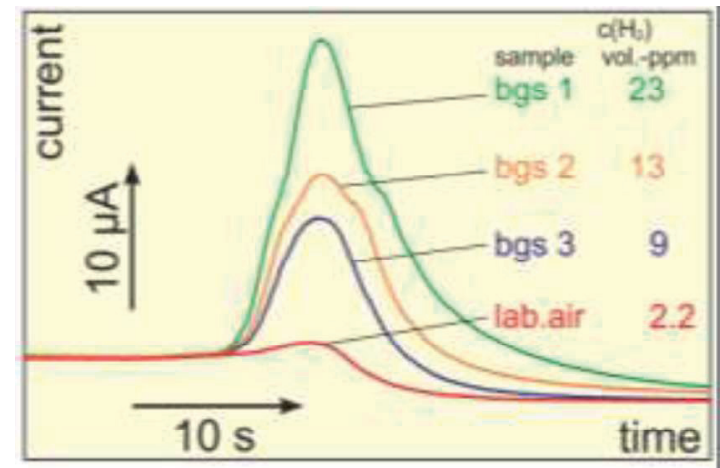

Fig. 10. Enlarged hydrogen peaks of chromatograms of breath gas samples (bgs) from different persons and laboratory air, measured with the setup in Fig. $1 C$.

\section{Conclusions}

By investigating different approaches which are focused on functional materials, electrochemical methods and chromatographic pre-separation of analytes from a matrix, the selectivity of solid electrolyte gas sensors was improved significantly without unfavorable influence on the other sensor parameters like sensitivity and long-term stability. The selection of the most suited approach depends on the requirements and further conditions of the application like response time, possibilities to calibrate the sensors, interfering gases or limits of operating costs. Future work should be focused on further clarification of electrode and electrolyte related processes with influence on the signal establishment. One the one hand, these results will enable the tailoring of the materials for particular applications as well as the optimum choice of the electrode conditioning with dynamic methods, temperature variations and flow modulations. On the other hand, the electrode materials play also an important role for the rapid and long-term stable detection of analytes after chromatographic separation. Therefore, the combination of the different approaches to enhanced selectivity will be the strategy of choice for the exploitation of new gas analysis applications with even more complex requirements in the future.

\section{References}

[1] H.-H. Möbius, Solid-state Electrochemical Potentiometric Sensors for Gas Analysis, In: W. Göpel, J. Hesse, J.N. Zemel, Sensors, Vol. 3, VCH, Weinheim, 1992, p. 1106-1154

[2] H. Ullmann, Keramische Gassensoren, Grundlagen-Aufbau-Anwendung, Akademie Verlag, Berlin, 1993, pp. 93-123

[3] T. Hübert, L. Boon-Brett, G. Black, U. Banach, Hydrogen Sensors - A review, Sens. Actuators, B, Chem. 157, 329-352 (2011); doi: 10.1016/j.snb.2011.04.070

[4] W. J. Buttner, M. B. Post, R. Burgess, C. Rivkin, An overview of hydrogen safety sensors and requirements, International Journal of Hydrogen Energy 36, 2462-2470 (2011); doi: 10.1016/j.ijhydene.2010.04.176

[5] T. Hübert, L. Boon-Brett, V. Palmisano, G. Frigo, Å. Hellstrand, O. Kiesewetter, M. May, Trends in gas sensor development for hydrogen safety, int. conf. on hydrogen safety, 2013 - Brussels - Belgium, proceedings

[6] S. Zhuiykov, Electrochemistry of Zirconia gas sensors, CRC press, London, 2007

[7] N. Miura, T. Raisen, G. Lu, N. Yamazoe, Highly selective $C O$ sensor using stabilized zirconia and a couple of oxide electrodes, Sens. Actuators, $B$, Chem. 47, 84-91 (1998); doi: 10.1016/S09254005(98)00053-7 
[8] J. Zosel, K. Ahlborn, R. Müller, D. Westphal, V. Vashook, U. Guth, Selectivity of HC-sensitive electrode materials for mixed potential gas sensors, Solid State lonics, 169, 115-119 (2004); doi: 10.1016/S0167-2738(03)00082-1

[9] X. Liang, B. Wang, H. Zhang, Q. Diao, B. Quan, G. Lu, Progress in solid electrochemical gas sensors based on NASICON and oxide electrodes, IMCS 2012 - The 14th International Meeting on Chemical Sensors; doi: 10.5162/IMCS2012/5.5.4

[10] J. Zosel, D. Tuchtenhagen, K. Ahlborn, U. Guth, Mixed potential gas sensor with short response time, Sens. Actuators, B, Chem. 130, 326-329 (2008); doi: 10.1016/j.snb.2007.08.008

[11] E.L. Brosha, R. Munkundan, D.R. Brown, F.H. Garzon, Mixed potential sensors using lanthanum manganate and terbium yttrium zirconium oxide electrodes, Sens. Actuators, B, Chem. 87, 47- 57 (2002); doi: 10.1016/S0925-4005(02)00216-2

[12] S. Yao, S. Hosohara, Y. Shimizu, N. Miura, H. Futata, N. Yamazoe, Solid Electrolyte $\mathrm{CO}_{2}$ Sensor Using NASICON and Li-based Binary Carbonate Electrode, Chem. Lett. 20, 2069-2072 (1991); doi: 10.1246/cl.1991.2069

[13] C. Yang, Z. Zhang, Y. Zhang, Multi-electrode solid electrolyte sensor for monitoring hydrogen and the adaptive identification algorithm of hydrogen concentration, 2013 IEEE 8th Conference on Industrial Electronics and Applications (ICIEA), Melbourne, VIC, 1059-1064 (2013); doi: 10.1109/ICIEA.2013.6566524

[14] K. Teske, P. Popp, J. Baumbach, Solid-state coulometric cell as detector for gas chromatography, Journal of Chromatography A 360, 417-420 (1986); doi 10.1016/S0021-9673(00)91690-X

[15] P. Shuk, E. Bailey, J. Zosel, U. Guth, New advanced in situ carbon monoxide sensor for the process application, lonics 15, 131138 (2009); doi: 10. 1007/s11581-008-0274-4

[16] E. Perumal, N. Miura, Influence of annealing temperature of $\mathrm{NiO}$ sensing-electrode on sensing characteristics of YSZ-based mixed-potentialtype $\mathrm{NO}_{x}$ sensor, In: C. Bruckner-Lea et. al (Eds.) Chemical Sensors VI: Chemical and Biological Sensors and Analytical Methods, Proceedings Volume 2004-08, The Electrochemical Soc. Inc. Pennington 2008, p. 82-88 (2004)

[17] S. Fischer, R. Pohle, B. Farber, R. Proch, J. Kaniuk, M. Fleischer, R. Moos, Method for detection of $\mathrm{NO}_{x}$ in exhaust gases by pulsed discharge measurements using standard zirconia-based lambda sensors, Sens. Actuators, B, Chem. 147, 780-785(2010); doi:10.1016/j.snb.2010.03.092
[18] M. Schelter, Entwicklung eines FestelektroIytsensor-Messsystems für die coulometrische Spurenanalytik, Dissertation, Technische Universität Dresden, p. 58-76, (2015)

[19] A. Jerger, H. Kohler, F. Becker, H. B. Keller, R. Seifert, New applications of tin oxide gas sensors II. Intelligent sensor system for reliable monitoring of ammonia leakages, Sens. Actuators, B, Chem. 81, 301-307(2002); doi: 10.1016/S09254005(01)00970-4

[20] C. Vonau, J. Zosel, M. Paramasivam, K. Ahlborn, F. Gerlach, V. Vashook, U. Guth, Polymer based materials for solid electrolyte sensors, Solid State Ionics 228, 337-341 (2012); doi: 10.1016/j.ssi.2012.04.015

[21] M. Schelter, J. Zosel, W. Oelßner, U. Guth, M. Mertig, Highly selective solid electrolyte sensor for the analysis of gaseous mixtures, J. Sens. Sens. Syst. 5, 319-324 (2016); doi: 10.5194/jsss5-319-2016

[22] M. Schelter, J. Zosel, W. Oelßner, U. Guth, M. Mertig, A solid electrolyte sensor for trace gas analysis, Sens. Actuators, B, Chem.187, 209-214 (2013); doi: 10.1016/j.snb.2012.10.111.

[23] J. Zosel, G. Schiffel, F. Gerlach, K. Ahlborn, U. Sasum, V. Vashook, U. Guth, Electrode materials for potentiometric hydrogen sensors, Solid State lonics 177, 2301-2304 (2006); doi: 10.1016/j.ssi.2006.01.004

[24] V. Vashook, J. Zosel, U. Guth, Oxygen Solid Electrolyte Coulometry (OSEC), J. Solid State Electrochem. 16, 3401-3421 (2012); doi: 10.1007/s10008-012-1876-3

[25] M. Schelter, J. Zosel, V. Vashook, U. Guth, M. Mertig, Electrolyte related parameters of coulometric solid state devices, Solid State lonics 288, 266-270 (2016); doi: 10.1016/j.ssi.2016.01.020

[26] M. Schelter, J. Zosel, W. Oelssner, U. Guth, M. Mertig, Verfahren zur selektiven Bestimmung redoxaktiver Gase in Gasgemischen mit einem Festelektrolytsensor, patent DE 102015008638 A1 (2017) 